\title{
Correction to: Edge Enhancement by Noise Suppression in HSI Color Model of UAV Video with Adaptive Thresholding
}

\author{
Ashish Srivastava $^{1}$ (D) Jay Prakash ${ }^{1}$ \\ Published online: 6 January 2022 \\ (c) Springer Science+Business Media, LLC, part of Springer Nature 2022
}

\section{Correction to: Wireless Personal Communications https://doi.org/10.1007/s11277-021-09334-x}

In this article four references were missing and should have been:

Burg, A. P., Keller, R., Wassner, J., Felber, N., \& Fichtner, W. (2000) A 3D-DCT realtime video compression system for low complexity single-chip VLSI implementation. In Proceedings of the Mobile Multimedia Conference.

Lee, M. C., Chan, R. K. W., \& Adjeroh, D. A. (1997) Quantization of 3D-DCT coefficients and scan order for video compression. Journal of Visual Communication and Image Representation, 8(4), 405-422.

Rong, W., Li, Z., Zhang, W., \& Sun, L. (2014) An improved CANNY edge detection algorithm. In IEEE International Conference on Mechatronics and Automation (pp. 577-582).

Yan, F., \& Chen, D.-F. (2013) Video reconstruction via online compressed sensing. Fifth International Conference on Digital Image Processing (ICDIP 2013). Journal International Society for Optics and Photonics, 88780.

The original article has been corrected.

Publisher's Note Springer Nature remains neutral with regard to jurisdictional claims in published maps and institutional affiliations.

The original article can be found online at https://doi.org/10.1007/s11277-021-09334-x.

Ashish Srivastava

ashish.srvstava88@gmail.com

Jay Prakash

jpr_1988@yahoo.co.in

1 Department of ITCA, Madan Mohan Malaviya University of Technology, Gorakhpur, India 